\title{
G1/S Cell Cycle Checkpoint Defect in Lymphocytes from Patients with Alzheimer's Disease
}

\author{
Misun Song', Young-Ah Kwon', Yujin Lee1, Hyeran Kim¹, Ji Hea Yun², Seonwoo Kim³ and Doh Kwan Kim,2凶 \\ 'Department of Psychiatry, Samsung Medical Center, Sungkyunkwan University School of Medicine, Seoul, Republic of Korea \\ ${ }^{2}$ Center for Clinical Research and ${ }^{3}$ Biostatistics Unit, Samsung Biomedical Research Institute, Seoul, Republic of Korea
}

Objective We compared the cell responsiveness of activated lymphocytes to rapamycin, which blocks the G1/S transition, between patients with Alzheimer's disease (AD) and normal controls to assess the early phase control defect in cell cycle.

Methods Blood samples of 26 patients with $\mathrm{AD}$ and 28 normal controls were collected to separate peripheral lymphocytes. We measured the proportion of each cell cycle phase in activated lymphocytes using flow cytometry and evaluated the responsiveness of these lymphocytes to rapamycin.

Results The patients with $\mathrm{AD}$ were older than the normal controls (AD 74.03 $\pm 7.90 \mathrm{yr}$ vs. control 68.28 $\pm 6.21 \mathrm{yr}, \mathrm{p}=0.004$ ). The proportion of G1 phase cells in the $\mathrm{AD}$ group was significantly lower than that in the control group $(70.29 \pm 6.32 \%$ vs. $76.03 \pm 9.05 \%$, $\mathrm{p}=0.01)$, and the proportion of $\mathrm{S}$ phase cells in the $\mathrm{AD}$ group was higher than that in control group $(12.45 \pm 6.09 \%$ vs. $6.03 \pm 5.11 \%$, $\mathrm{p}=0.001)$. Activated lymphocytes in patients with $\mathrm{AD}$ were not arrested in the $\mathrm{G} 1$ phase and they progressed to the late phase of the cell cycle despite rapamycin treatment, in contrast to those of normal subjects.

Conclusion The patients with AD probably have a control defect of early phase cell cycle in peripheral lymphocytes that may be associated with the underlying pathology of neuronal death.

Psychiatry Investig 2012;9:413-417

Key Words Alzheimer's disease, Cell cycle, Biomarker.

\section{INTRODUCTION}

A defect in cell cycle control appears early in Alzheimer's disease $(\mathrm{AD})$ pathogenesis, when patients are not yet clinically demented. ${ }^{1,2}$ Cellular pathology in patients with $\mathrm{AD}$ is not restricted to neurons ${ }^{3,4}$ and can be observed as a defect in cell cycle control in peripheral nucleated cells. ${ }^{5-7}$ We found previously that cell viability of lymphocytes in patients with $\mathrm{AD}$ decreases more rapidly after phytohemagglutinin (PHA) stimulation than that in a normal control. ${ }^{8} \mathrm{PHA}$ is a lectin found in plants and is used as a mitogen to trigger lymphocyte cell division.

Re-entry of differentiated neuronal cells into the cell division cycle in the brain is followed by a cell cycle regulation de-

Received: March 2, 2012 Revised: June 15, 2012

Accepted: July 25, 2012 Available online: November 12, 2012

$\triangle$ Correspondence: Doh Kwan Kim, MD

Department of Psychiatry, Samsung Medical Center, Sungkyunkwan University School of Medicine, 50 Irwon-dong, Gangnam-gu, Seoul 135-710, Republic of Korea

Tel: +82-2-3410-3582, Fax: +82-2-3410-0941, E-mail: paulkim@skku.edu

(a) This is an Open Access article distributed under the terms of the Creative Commons Attribution Non-Commercial License (http://creativecommons.org/licenses/by$\mathrm{nc} / 3.0$ ) which permits unrestricted non-commercial use, distribution, and reproduction in any medium, provided the original work is properly cited. fect in patients with $\mathrm{AD} \cdot{ }^{9-11}$ During healthy aging, the regulatory mechanisms that inhibit the G1/S transition in the cell cycle, the "point of no return", beyond which the cell is committed to dividing, are activated, so the neuronal cell division cycle does not progress beyond the G1 phase. However, the G1/S regulatory mechanism seems to be dysfunctional in patients with $\mathrm{AD}$, and the neuronal cell cycle is allowed to progress as far as the G2 phase. As neurons are not capable of undergoing mitosis and completing the cell cycle, these cells may die via apoptosis or produce $\mathrm{AD}$-related pathologies..$^{10,12}$

We hypothesized that this known cell cycle regulation defect at the G1/S checkpoint may be reflected in peripheral lymphocytes. To assess the function of the G1/S transition checkpoint, we compared the responsiveness of activated lymphocytes to a G1/S transition inhibitor between patients with $\mathrm{AD}$ and normal controls.

\section{METHODS}

\section{Subjects}

Patients with $\mathrm{AD}$ from the Clinical Trials Program at the Geropsychiatric Clinic at Samsung Medical Center were includ- 
ed in the study. These patients were a completely separate sample from our previous report. ${ }^{8}$ Patients were diagnosed as "probable Alzheimer's disease" using the NINCDS-ADRDA (The National Institute of Neurological and Communicative Disorders and Stroke and the Alzheimer's Disease and Related Disorders Association) diagnostic criteria. All patients underwent a neuropsychological evaluation, routine laboratory tests, a neurological examination, and neuroimaging (brain magnetic resonance imaging) to rule out other causes of dementia. The Korean version of the Mini Mental State Examination (K-MMSE) ${ }^{13}$ Clinical Dementia Rating (CDR), ${ }^{14}$ Seoul-Instrumental Activity of Daily Living (S-IADL) ${ }^{15}$ and Seoul-Activity of Daily Living Scale (S-ADL) $)^{16}$ were administered. Patients with other significant psychiatric, neurological, or medical illnesses were excluded.

The normal control subjects consisted of elderly volunteers who responded to an advertisement. They were evaluated by a psychiatrist based on the Health Screening Exclusion Crite$\mathrm{ria}^{17}$ to ensure the absence of medical, neurological, and psychiatric problems. All subjects met the following inclusion criteria: 1) free of memory and cognitive disorders; 2) lived independently without difficulty; 3) no active psychiatric illness, alcohol/drug history; and 4) no active medical or neurological disorder including human cytomegalovirus infection, hypoxia, and certain cancers that could potentially affect cognition and the G1/S transition. ${ }^{18-21}$ In addition, the K-MMSE, the 7 Minute Screening Test, ${ }^{22}$ S-IADL, and S-ADL were administered by an independent clinical psychologist.

With the approval of the Institutional Review Board at the Samsung Medical Center, 26 patients with AD and 28 normal controls participated and completed this study. Signed informed consent was obtained from all participants.

\section{Separation and culture of peripheral lymphocytes}

Blood samples from the patients and normal controls were collected to separate peripheral lymphocytes. Blood samples were heparinized, stored at $4^{\circ} \mathrm{C}$ immediately after venipuncture, and assayed within $24 \mathrm{hr}$. Peripheral blood mononuclear cells were isolated by centrifugation at $300 \times \mathrm{g}$ for $15 \mathrm{~min}$ on a Ficoll-Hypaque (Pharmacia Biotech, Uppsala, Sweden) density gradient. The cells were washed twice with phosphate buffered saline (Sigma, St. Louis, MO, USA), and the lymphocytes were separated in Hank's balanced salt solution (Sigma). We defined this point as $\mathrm{T}_{0}$ (baseline). After $20 \mu \mathrm{g} / \mathrm{mL}$ of PHA (Gibco, Grand Island, NY, USA) was added to reactivate the cell cycle, the lymphocytes were cultured in RPMI1640 (Gibco) containing $10 \%$ fetal bovine serum at $37^{\circ} \mathrm{C}$ with $5 \% \mathrm{CO}_{2}$ for $24 \mathrm{hr}$. These lymphocytes were then treated with $100 \mathrm{ng} /$ $\mathrm{mL}$ rapamycin (Sigma) and cultured for an additional $24 \mathrm{hr}$ under the previous conditions. We defined this point as $\mathrm{T}_{48}$.
Rapamycin is an immunosuppressant drug used to prevent organ transplant rejection. It prevents lymphocytes from activating by inhibiting their response to interleukin-2. We assumed that rapamycin would inhibit the G1/S transition. ${ }^{23}$ We measured cell numbers in the cell cycle stages, as indicated below, to assess the $\mathrm{G} 1 / \mathrm{S}$ transition control at $\mathrm{T}_{0}$ and $\mathrm{T}_{48}$.

\section{Assessment of G1/S transition checkpoint function}

The cultured lymphocytes were fixed in $70 \%$ ethanol at $4^{\circ} \mathrm{C}$ for $10 \mathrm{~min}$ to measure cell number in each stage. The samples $\left(1 \times 10^{6}\right.$ cells for each) were washed twice with ice-cold phosphate buffered saline, and incubated with RNase, DNA intercalating dye, and $2.0 \mathrm{~mL}$ of DAPI (Cystain DNA 1step, Partec, Görlitz Germany). We used a PAS flow cytometer (Partec) and the ModFit LT 3.0 Partec software to measure the proportion of cells in each cell cycle phase (Fig. 1A). At least $1 \times 10^{4}$ events were analyzed, and the assay was repeated twice. We evaluated the proportion of $\mathrm{G} 1$ and $\mathrm{S}$ phases at $\mathrm{T}_{0}$ and $\mathrm{T}_{48}$ from the patients with $\mathrm{AD}$ and the normal controls.

\section{Statistical analysis}

We used the independent two-sample t-test and the MannWhitney test with Bonferronis correction to evaluate the difference in the proportion of $\mathrm{G} 1$ and $\mathrm{S}$ phase cells between the patients with $\mathrm{AD}$ and normal controls at each point. Pearson's partial correlation and Spearman's partial correlation analyses were applied to adjust for age. The paired t-test and Wilcoxon's signed-rank test with Bonferroni's correction were used to evaluate the differences in the cell cycle phase between $T_{0}$ and $\mathrm{T}_{48}$ in each group. The relationships between the proportion of G1 phase cells at $\mathrm{T}_{48}$ and the clinical scores reflecting disease severity (CDR, K-MMSE, S-IADL, S-IADL, and duration of illness) in patients with $\mathrm{AD}$ were tested using Pearson's correlation and Spearman's correlation analyses. We divided the patients with $\mathrm{AD}$ into three groups according to their $\mathrm{CDR}$ score (CDR score 0.5 or $1, \mathrm{CDR}$ score 2 , and CDR score 3 ). The differences in the proportion of G1 phase cells at $\mathrm{T}_{48}$ among these groups were evaluated using the Kruskal-Wallis test.

\section{RESULTS}

\section{Subject characteristics}

No significant differences were observed in the female/ male ratio (AD 16/10 vs. control 19/9, $\mathrm{p}=0.62$ ) or educational status ( $\mathrm{AD} 8.76 \pm 5.42$ years vs. control $10.39 \pm 4.21 \mathrm{yr}, \mathrm{p}=0.22$ ) between the patients with $\mathrm{AD}$ and normal controls. The patients with $\mathrm{AD}$ were older than that of the normal controls (AD 74.03 \pm 7.90 yr vs. control $68.28 \pm 6.21 \mathrm{yr}, \mathrm{p}=0.004$ ), so all results were adjusted for age. The patients with $\mathrm{AD}$ had mild to severe dementia with a mean K-MMSE score of 17.34 (SD, 


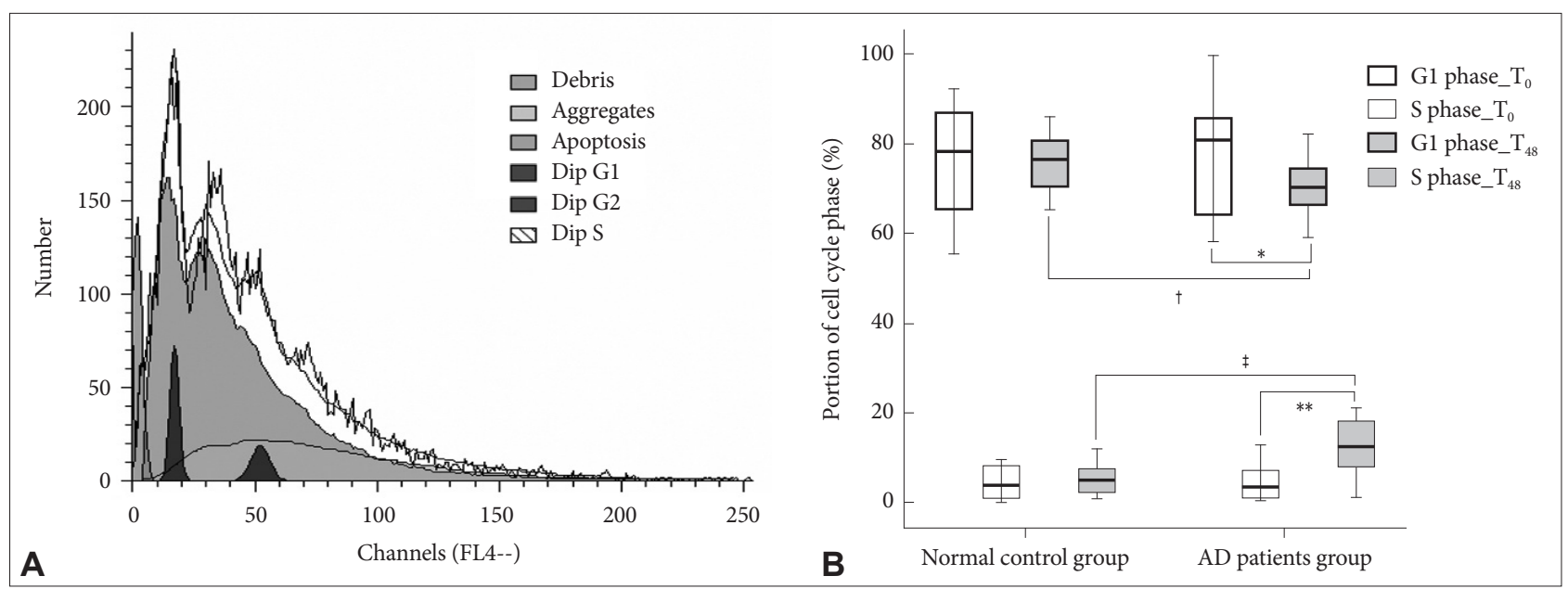

Figure 1. A: Analysis of the cell cycle phase using a PAS flow cytometer. This figure is a graph obtained by the PAS flow cytometer produced during an assay of peripheral lymphocytes. It shows the distribution of cells according to their DNA. Each cell was categorized as G1 or S phase based on DNA content, and the proportions of the cell cycle phases were calculated using ModFit LT 3.0 Partec software. B: Comparison of the cell cycle between patients with Alzheimer's disease and normal control subjects. Mean value of the proportion of cells in the G1 and S phase by the cell cycle analysis of peripheral lymphocytes. *the proportion of cells in the G1 phase at $T_{48}$ was lower than that at $T_{0}(p=0.02),{ }^{* *}$ the proportion of cells in the $S$ phase at $T_{48}$ was higher than that at $T_{0}(p=0.002)$ in patients with $A D$, the proportion of G1 phase cells at $T_{48}$ in patients with AD was lower than that in the normal control subjects $(p=0.01)$, *the proportion of $S$ phase cells in the patients with $A D$ was higher than that in the normal control subjects $(p=0.001)$. Dip: diploid, AD: Alzheimer's disease.

Table 1. The baseline demographic and clinical characteristics of the patients with Alzheimer's disease and normal control subjects

\begin{tabular}{lccc}
\hline & $\begin{array}{c}\text { Alzheimer's disease } \\
(\mathrm{N}=26)\end{array}$ & $\begin{array}{c}\text { Normal control } \\
(\mathrm{N}=28)\end{array}$ & p-value \\
\hline Gender, F/M & $16 / 10$ & $19 / 9$ & $0.62^{*}$ \\
Age (yr) & $74.03 \pm 7.90$ & $68.28 \pm 6.21$ & $0.004^{\dagger}$ \\
Education (yr) & $8.76 \pm 5.42$ & $10.39 \pm 4.21$ & $0.22^{\dagger}$ \\
K-MMSE & $17.34 \pm 6.26$ & $27.25 \pm 1.60$ & $<0.001^{\ddagger}$ \\
CDR score & & 0 & \\
0.5 or 1 & $\mathrm{~N}=16$ & & \\
2 & $\mathrm{~N}=8$ & & \\
3 & $\mathrm{~N}=2$ & & \\
\hline
\end{tabular}

Data are mean \pm standard deviations (SD). Results are considered significant at $\mathrm{p}<0.05$. ${ }^{*}$ Chi-square test, ${ }^{\dagger} \mathrm{t}$-test, ${ }^{\ddagger}$ Mann-Whitney test. F/M: female/male, K-MMSE: Korean version of the Mini Mental State Examination, CDR: Clinical Dementia Rating

6.26). Sixteen patients had CDR scores of 0.5 or 1 , eight had a CDR score of 2 , and two had a CDR score of 3 (Table 1 ). A total of 24 patients received cognitive enhancers [donepezil $(n=7)$, galantamine $(n=13)$, or memantine $(n=4)]$ and two patients received sertraline. We divided the patients into subgroups according to their medications. No significant differences were observed for gender, age, education, K-MMSE, or CDR scores among the subgroups taking cognitive enhancers, as well as among the four subgroups taking any medication.

\section{Analysis of cell cycle phase at $\mathrm{T}_{0}$ and $\mathrm{T}_{48}$}

We found (i) A $24 \mathrm{hr}$ PHA incubation followed by a $24 \mathrm{hr}$ rapamycin incubation resulted in no net change in the G1 and $\mathrm{S}$ phases in control subjects; (ii) there was evidence of activation of the cell cycle (fewer in G1 and more in S phases) in patients with $\mathrm{AD}$. The cell cycle analysis at $\mathrm{T}_{0}$ did not show any differences between the $\mathrm{AD}$ and control groups (G1 phase; $p>0.99$, S phase; $p>0.99$ ). After cell cycle reactivation at $\mathrm{T}_{48}$ and following the rapamycin treatment, the proportion of G1 phase cells in the AD group was lower than that in the control group $(70.29 \pm 6.32 \%$ vs. $76.03 \pm 9.05 \%, p=0.01)$ and the proportion of $\mathrm{S}$ phase cells in the $\mathrm{AD}$ group was higher than that in the control group $(12.45 \pm 6.09 \%$ vs. $6.03 \pm 5.11 \%$, $\mathrm{p}=0.001$ ) after adjusting for age (Table 2 and Fig. 1B).

We compared the cell cycle between $\mathrm{T}_{0}$ and $\mathrm{T}_{48}$ in each group. The cell cycle in the control group at $\mathrm{T}_{48}$ was not different from that at $\mathrm{T}_{0}$ (G1 phase; $\mathrm{p}>0.99, \mathrm{~S}$ phase; $\left.\mathrm{p}>0.99\right)$. The proportion of $\mathrm{G} 1$ phase cells at $\mathrm{T}_{48}$ in the $\mathrm{AD}$ group was significantly lower than that at $\mathrm{T}_{0}(70.29 \pm 6.32 \%$ vs. $77.05 \pm$ $11.69 \%, \mathrm{p}=0.02$ ), and the proportion of $\mathrm{S}$ phase cells at $\mathrm{T}_{48}$ was higher than that at $\mathrm{T}_{0}(12.45 \pm 6.09 \%$ vs. $5.80 \pm 7.40 \%, \mathrm{p}=$ 0.002) (Fig. 1B). We also compared the cell cycle at $\mathrm{T}_{0}$ and $\mathrm{T}_{48}$ in each subgroup according to the medications to exclude the influence of medication, and no significant differences in the cell cycle analysis were observed among the subgroups.

\section{Disease severity and G1/S transition control}

No correlation was found between the proportion of G1 phase cells at $\mathrm{T}_{48}$ and the clinical scores reflecting dementia severity (CDR, K-MMSE, S-IADL, S-ADL, and duration of illness) in the AD group (CDR, $\rho=0.14, p=0.49$; K-MMSE, $r=$ $0.25, p=0.22$; S-IADL, $r=-0.19, p=0.34$; $-A D L, \rho=-0.05, p=$ 
Table 2. The proportion of cells in the G1 and S cycle phases in patients with Alzheimer's disease and normal control subjects

\begin{tabular}{lccccc}
\hline & \multicolumn{2}{c}{$\mathrm{T}_{0}$} & & \multicolumn{2}{c}{$\mathrm{T}_{48}$} \\
\cline { 2 - 3 } \cline { 5 - 6 } & $\mathrm{G} 1(\%)$ & $\mathrm{S}(\%)$ & $\mathrm{G} 1(\%)$ & $\mathrm{S}(\%)$ \\
\hline Alzheimer's disease & $77.05 \pm 11.69$ & $5.80 \pm 7.40$ & & $70.29 \pm 6.32$ & $12.45 \pm 6.09$ \\
Normal control & $76.32 \pm 11.33$ & $6.15 \pm 8.44$ & & $76.03 \pm 9.05$ & $6.03 \pm 5.11$ \\
p-value & $>0.99^{*}$ & $>0.99^{\dagger}$ & & $0.01^{*}$ & $0.001^{\dagger}$ \\
\hline
\end{tabular}

Data are mean \pm standard deviation. Results are considered significant at $\mathrm{p}<0.05$. All results are adjusted for age. Bonferroni's correction was applied for multiple testing (multiplying $\mathrm{p}$-value and the number of tests). $\mathrm{T}_{0}$ : baseline, $\mathrm{T}_{48}$ : 24-hour culture after phytohemagglutinin stimulation and then additional 24-hour culture after rapamycin treatment. *Pearson's partial correlation analysis, †Spearman's partial correlation analysis

0.80; duration of illness, $\mathrm{r}=-0.13, \mathrm{p}=0.53)$.

\section{DISCUSSION}

When peripheral lymphocytes from patients with $\mathrm{AD}$ were activated with PHA and then treated with the G1/S transition inhibitor rapamycin, the cells displayed a significantly greater proportion of late $S$ phase stage cells in comparison to cells from control subjects. This demonstrates that the peripheral lymphocytes from patients with $\mathrm{AD}$ were less responsive to rapamycin. These data support the hypothesis that the known defect in the G1/S checkpoint in neurons from patients with $\mathrm{AD}$ is reflected in peripheral lymphocytes. These results correspond with a previous study that reported poor responsiveness to rapamycin by peripheral lymphocytes from patients with $\mathrm{AD} .^{6}$ That previous study analyzed the relative lengthening of the G1 phase of the cell cycle, which was calculated based on many assumptions. We validated their findings by evaluating the proportion of G1 and S phase cells in the cell cycle based on flow cytometry.

We assumed that there might be some defect in cell cycle control in peripheral lymphocytes as well as in neurons from patients with $\mathrm{AD}$. The fate of cells that are unable to complete mitosis depends on the phase in which the cycle was arrested. ${ }^{10}$ Cells in early G1 phase are able to exit the cycle and redifferentiate. However redifferentiation is no longer possible if the cells have reached the G2 phase $\mathrm{e}^{24}$ and the cells then have one of two fates; they either die via a mechanism that resembles apoptosis or survive and produce $\mathrm{AD}$ pathology. ${ }^{25}$ The dysregulation of the G1/S transition checkpoint is necessary for AD pathogenesis. ${ }^{6}$

We found that G1/S transition control had no correlation with clinical scores reflecting disease severity. Nagy et al. ${ }^{6}$ suggested that the lymphocyte response in subjects showing neuropsychological signs of preclinical $\mathrm{AD}$ is similar to that seen in patients with $A D$. This indicates that a defect in G1/S transition control in peripheral lymphocytes of patients with $\mathrm{AD}$ is not affected by the disease course and may represent the disease entity of AD. Thus, G1/S regulatory failure detected in peripheral lymphocytes might be an early biological mani- festation of AD. Our results support the possibility that peripheral lymphocytes may reflect the situation in the brain. An increasing body evidence indicates that peripheral lymphocytes may be exploited as a neural and possible genetic probe in psychiatric disorder studies. ${ }^{5,7}$ The use of brain biopsies of living patients is unrealistic for biochemical studies, and lymphocytes may be a convenient and accessible alternative. $\mathrm{Nu}-$ merous studies on psychiatric disorders have shown that alterations in metabolism and cellular function in the central nervous system, as well as disturbances in the main neurotransmitter and hormonal systems are concomitant with altered cellular and metabolic functions in peripheral lymphocytes. $^{26,27}$

We tried to minimize other influences by excluding patients with other significant psychiatric, neurological, or medical illnesses. Our results do not identify the mechanism of the G1/S dysregulation that was manifested as a poor response of peripheral lymphocytes to rapamycin. Further research must be conducted to elucidate the nature of the G1/S regulatory failure, particularly on the cell cycle regulatory proteins and genetic components that are responsible for such a defect. Additionally, prospective studies will be required to evaluate the diagnostic potential of these findings.

\section{Acknowledgments}

This study was supported by a grant from the National Research Foundation of Korea funded by the Korean government (MEST, R0A 2007-00020129-0) and the Korea Health 21 R\&D Project funded by the Ministry of Health \& Welfare (A030001), Republic of Korea.

\section{REFERENCES}

1. Elias MF, Beiser A, Wolf PA, Au R, White RF, D’Agostino RB. The preclinical phase of alzheimer disease: a 22-year prospective study of the Framingham Cohort. Arch Neurol 2000;57:808-813.

2. Raina AK, Monteiro MJ, McShea A, Smith MA. The role of cell cyclemediated events in Alzheimer's disease. Int J Exp Pathol 1999;80:71-76.

3. Cotman CW, Anderson AJ. A potential role for apoptosis in neurodegeneration and Alzheimer's disease. Mol Neurobiol 1995;10:19-45.

4. Rissman RA, Poon WW, Blurton-Jones M, Oddo S, Torp R, Vitek MP, et al. Caspase-cleavage of tau is an early event in Alzheimer disease tangle pathology. J Clin Invest 2004;114:121-130.

5. Gladkevich A, Kauffman HF, Korf J. Lymphocytes as a neural probe: potential for studying psychiatric disorders. Prog Neuropsychopharmacol Biol Psychiatry 2004;28:559-576. 
6. Nagy Z, Combrinck M, Budge M, McShane R. Cell cycle kinesis in lymphocytes in the diagnosis of Alzheimer's disease. Neurosci Lett 2002;317:81-84.

7. Araga S, Kagimoto H, Funamoto K, Takahashi K. Lymphocyte proliferation and subpopulations in dementia of the Alzheimer type. Jpn J Med 1990;29:572-575.

8. Yoon SC, Kwon YA, Kim H, Kim S, Ahn Jo S, Kim DK. Altered cell viability and proliferation activity of peripheral lymphocytes in patients with Alzheimer's disease. Psychiatry Investig 2010;7:68-71.

9. Cummings JL, Cole G. Alzheimer disease. JAMA 2002;287:2335-2338.

10. Nagy Z. The last neuronal division: a unifying hypothesis for the pathogenesis of Alzheimer's disease. J Cell Mol Med 2005;9:531-541.

11. Herrup K, Neve R, Ackerman SL, Copani A. Divide and die: cell cycle events as triggers of nerve cell death. J Neurosci 2004;24:9232-9239.

12. Nagy Z. Cell cycle regulatory failure in neurones: causes and consequences. Neurobiol Aging 2000;21:761-769.

13. Kang Y, Na DL, Hahn S. A validity study on the Korean Mini-Mental State Examination (K-MMSE) in dementia patients. J Korean Neurol Assoc 1997;15:300-308.

14. Morris JC. The Clinical Dementia Rating (CDR): current version and scoring rules. Neurology 1993;43:2412-2414.

15. Ku HM, Kim JH, Kwon EJ, Kim SH, Lee HS, Ko HJ, et al. A study on the reliability and validity of Seoul Instrumental Activities of Daily Living (S-IADL). J Korean Neuropsychiatr Assoc 2004;43:189-199.

16. Ku HM, Kim JH, Lee HS, Ko HJ, Kwon EJ, Jo S, et al. A study on the reliability and validity of Seoul-Activities of Daily Living (S-ADL). J Korean Geriatr Soc 2004;8:206-214

17. Christensen KJ, Multhaup KS, Nordstrom S, Voss K. A cognitive battery for dementia: Development and measurement characteristics. Psychol
Assess 1991;3:168-174.

18. Ivnik RJ, Malec JF, Smith GE, Tangalos EG, Petersen RC, Kokmen E. Mayos older americans normative studies: Updated AVLT norms for ages 56 to 97. Clin Neuropsychol 1992;6(Suppl 1):83-104.

19. Petersen RC. Mild cognitive impairment as a diagnostic entity. J Intern Med 2004;256:183-194

20. Dittmer D, Mocarski ES. Human cytomegalovirus infection inhibits G1/S transition. J Virol 1997;71:1629-1634.

21. Gardner LB, Li Q, Park MS, Flanagan WM, Semenza GL, Dang CV. Hypoxia inhibits G1/S transition through regulation of p27 expression. J Biol Chem 2001;276:7919-7926.

22. Ku HM, Kim JH, Ko SG, Ko HJ, Lee HS, Kim SY, et al. Clinical efficacy of the individual tests in 7 Minute Screen Test (7MS). J Korean Neuropsychiatr Assoc 2005;44:253-258.

23. Battaglia M, Stabilini A, Roncarolo MG. Rapamycin selectively expands CD4+CD25+FoxP3+ regulatory T cells. Blood 2005;105:4743-4748.

24. Meikrantz W, Schlegel R. Apoptosis and the cell cycle. J Cell Biochem 1995;58:160-174.

25. McShea A, Wahl AF, Smith MA. Re-entry into the cell cycle: a mechanism for neurodegeneration in Alzheimer disease. Med Hypotheses 1999;52:525-527.

26. Richartz-Salzburger E, Batra A, Stransky E, Laske C, Kohler N, Bartels $\mathrm{M}$, et al. Altered lymphocyte distribution in Alzheimer's disease. J Psychiatr Res 2007;41:174-178.

27. Mizrahi C, Stojanovic A, Urbina M, Carreira I, Lima L. Differential cAMP levels and serotonin effects in blood peripheral mononuclear cells and lymphocytes from major depression patients. Int Immunopharmacol 2004;4:1125-1133. 